\title{
Solar Thermal Aquaculture System Controller Based on Artificial Neural Network
}

\author{
Doaa M. Atia ${ }^{1}$, Faten H. Fahmy ${ }^{1}$, Ninet M. Ahmed ${ }^{1}$, Hassen T. Dorrah ${ }^{2}$ \\ ${ }^{1}$ Electronics Research Institute, Cairo, Egypt \\ ${ }^{2}$ Electrical Power and Machines, Faculty of Engineering,Cairo Univ. Cairo, Egypt \\ E-mail:doaa_matia@yahoo.com \\ Received December 16, 2010; revised July 5, 2011; accepted July 15, 2011
}

\begin{abstract}
Temperature is one of the most principle factors affects aquaculture system. The water temperature is very important parameter for shrimp growth. It can cause stress and mortality or superior environment for growth and reproduction. The required temperature for optimal growth is $34^{\circ} \mathrm{C}$, if temperature increase up to $38^{\circ} \mathrm{C}$ it causes death of the shrimp, so it is important to control water temperature. Solar thermal water heating system is designed to supply an aquaculture pond with the required hot water in Mersa Matruh in Egypt as presented in this paper. This paper introduces a complete mathematical modeling and MATLAB SIMULINK model for the solar thermal aquaculture system. Moreover the paper presents the control of pond water temperature using artificial intelligence technique. Neural networks are massively parallel processors that have the ability to learn patterns through a training experience. Because of this feature, they are often well suited for modeling complex and non-linear processes such as those commonly found in the heating system. They have been used to solve complicated practical problems. The simulation results indicate that, the control unit success in keeping water temperature constant at the desired temperature by controlling the hot water flow rate.
\end{abstract}

Keywords: Aquaculture, Forced Circulation Hot Water System, Artificial Neural Networks

\section{Introduction}

The shrimp farming is an important economical activity in many countries [1]. Intensive aquaculture is a modern cultivation way and it develops fast in many countries. Recently, People pay more and more attention on aquaculture for its advantages of high yield, no-time-limit, low-feed and high-utilization of water [2]. The purpose for applying process control technology to aquaculture in developed countries encompasses many socioeconomic factors, including variable climate. Anticipated benefits for aquaculture process control systems are to be increased process efficiency, reduced energy and water losses, reduced labor costs, reduced stress and disease, improved accounting, improved understanding of the process [3].

The study of artificial neural networks (ANN) is one of the two major branches of intelligence control, which is based on the concept of artificial intelligence (AI). AI can be defined as computer emulation of the human thinking process. During the last ten years, there has been a substantial increase in the interest on artificial neural networks. During the last ten years, there has been a substantial increase in the interest on artificial neural networks. The ANNs are good for some tasks while lacking in some others. Specifically, they are good for tasks involving incomplete data sets, fuzzy or incomplete information and for highly complex and ill-defined problems, where humans usually decide on an intuitional basis [4-6]. In this paper the control of water temperature of aquaculture system is achieved. ANN control is chosen to this task due to high efficiency in control application.

\section{Mathematical Model of Solar Thermal System}

Storage tank temperature is an important parameter which influences the system size and performance. Energy balance of a well mixed storage tank can be expressed as [7]

$$
\rho V_{s} c_{p} \frac{\mathrm{d} T_{s t}}{\mathrm{~d} t}=q_{c}-q_{l}-q_{s t l}
$$


where $\rho$ water density $\left(\mathrm{kg} / \mathrm{m}^{3}\right), V_{s}$ is is storage tank volume $\left(\mathrm{m}^{3}\right), T_{s t}$ is storage tank temperature $\left({ }^{\circ} \mathrm{C}\right), C_{p}$ is specific heat of water $\left(4190 \mathrm{~J} / \mathrm{kg} \cdot{ }^{\circ} \mathrm{C}\right), q_{c}$ is actual useful energy gain, $q_{l}$ is load energy, and $q_{s t}$ is storage tank losses.

\subsection{Flat Plate Collector Modeling}

Solar useful heat gain rate $\left(q_{c}\right)$ from the collector array is calculated by

$$
q_{c}=F_{R} A_{c}\left[\alpha \tau G-U_{l}\left(T_{i}-T_{a}\right)\right]^{+}
$$

where $q_{c}$ represents actual useful energy gain (W), $F_{R}$ the collector heat removal factor, $G$ intensity of solar radiation, in $\left(\mathrm{W} / \mathrm{m}^{2}\right), A_{c}$ collector surface area $\left(\mathrm{m}^{2}\right),(\alpha \tau)$ is the transmittance absorptance product, $U_{l}$ is collector overall heat transfer coefficient $\left(\mathrm{W} / \mathrm{m}^{2} \cdot{ }^{\circ} \mathrm{C}\right), T_{a}$ is the ambient temperature $\left({ }^{\circ} \mathrm{C}\right)$, and $T_{i}$ is the inlet temperature. Where + sign indicates that only positive values of $q_{c}$ is considered in the analysis. This implies that hot water from the collector enters the tank only when solar useful heat gain becomes positive [7].

\subsection{Mathematical Modeling of the Aquaculture Pond}

A numerical model based on energy balance was developed to simulate the thermal behavior of the open-pond system. Assumed uniform temperature for the entire pond, and thus applied a well-mixed model [8].

\subsubsection{Evaporation Losses}

The evaporation heat loss is the largest loss component and is given

$$
q_{e}=A_{p} P_{a}\left[35 V+43\left(T_{p}-T_{a}\right)^{1 / 3}\right]\left(\omega_{p}-\omega_{a}\right)
$$

where $q_{e}$ is the evaporation loss (W), $V$ is the wind speed in $(\mathrm{m} / \mathrm{s})$ in the vicinity of the pond, $P_{a}$ the ambient air pressure $(101.3 \mathrm{k} \cdot \mathrm{Pa}) . T_{P}$ is the pond temperature, $T_{a}$ is the ambient temperature, $\omega_{P}$ is the saturation humidity ratio at the pond temperature, $\omega_{a}$ is the humidity ratio of the ambient air above the pond, $A_{p}$ is the area of the pond $[8,9]$.

\subsubsection{Convection Losses}

Heat losses due to convection to the ambient air can be expressed as $[8,9]$

$$
q_{c}=q_{e} \times 0.0006 \frac{T_{p}-T_{a}}{\omega_{p}-\omega_{a}}
$$

\subsubsection{The Net Radiation Losses}

Results from the surface of the pond to the sky which can be expressed as $[8,9]$ :

$$
q_{r}=\varepsilon \sigma A_{p}\left[\left(T_{p}+273\right)^{4}-T_{s}^{4}\right]
$$

where $q_{r}$ is the radiation loss, $\varepsilon$ is the emissivity of the surface, $\sigma$ is the Stefan-Boltzmann constant, $T_{S}$ is the sky temperature in degrees Kelvin, $T_{p}$ is the pond temperature.

\subsubsection{Solar Radiation Heat Gain}

Heat gain due to the absorption of solar radiation by the pond is given by $[8,9]$

$$
q_{s}=\alpha A_{p} G
$$

where $\alpha$ is pond absorptance (0.9).

\subsection{The Control Thermostatic Valve Modeling}

The required characteristic of this valve must be linear, such that controlling the valve input signal, will directly control the mass flow rate of water. Therefore, the transfer function of the used valve will be considered to be a first order one, as

$$
G_{v}(s)=\frac{1}{s+1}
$$

\section{Required Pond Design}

The pond is selected to be a rectangular shape as shown in Figure 1. The parameters of the pond are indicated in Table 1.

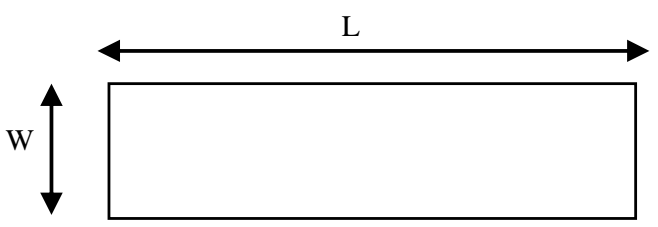

(a)

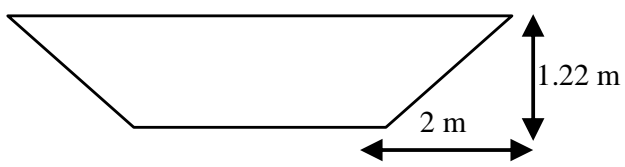

(b)

Figure 1. Pond design (a) Pond dimension; (b) Pond cross section detail.

Table 1. The pond dimension.

\begin{tabular}{ccc}
\hline Length (m) & $L$ & 20 \\
Width (m) & $W$ & 8 \\
Depth (m) & $d$ & 1.22 \\
Volume $\left(\mathrm{m}^{3}\right)$ & $V$ & 168 \\
Area $\left(\mathrm{m}^{2}\right)$ & $A$ & 64 \\
\hline
\end{tabular}




\section{Neural Network Description}

In recent years, neural solutions have been suggested for many industrial systems using either feed-forward or recurrent neural networks. The ANN is usually made up of activation function neurons and training algorithm is normally used to train the network either online or offline. Some applications use neurons with a radial base activation function. The ANN may play different roles: plant identification, non-linear controller, and fault signaling. Typical neural networks used for identification purposes are multilayer feed-forward structures containing neurons with activation function. There are two configurations for plant identification: the forward configuration and the inverse configuration [10-12]. A neural network consists of a number of processing elements "neurons" each of which have many inputs but only one output. In a typical network there are three layers of neurons, which are input layer receives input from the outside world, hidden layer which receive inputs from the input layer neurons and the output layer which receives inputs from the hidden layers and passes its output to the outside world and in some cases back to the preceding layers. In a feed forward neural network, the value of each node in a particular hidden layer is the result of a non linear transfer function a whose argument is the weighted sum over all the nodes in the previous layer plus a constant term $b$ which is referred to as the bias as presents in Equation (8)

$$
x_{i}=\sum_{j} y_{j} W_{i j}+b
$$

The $j$ subscript refers to a summation of all nodes in the previous layer of nodes and the $i$ subscript refers to the node position in the present layer. In order to solve for the weight and bias values of Equation (8) for all nodes, one requires a set of input patterns, representative of the system behavior. A variety of training algorithms are available but in general, to train a network, one begins with a set of training data consisting of the input vector, and corresponding target vector. The internal weights are adjusted until the sum of differences between the neural network outputs and the corresponding target is minimized to a pre-determined level for all the training data. A sigmoidal function is usually used for the transfer function as it enables a finite number of nodes in a single hidden layer to uniformly approximate any continuous function

$$
y_{j}=\frac{1}{1+\mathrm{e}^{-x j}}
$$

\subsection{The Error Back-Propagation Algorithm}

The most popular supervised training algorithm is the one named "error back-propagation”, or simply "backpropagation”. It involves training a FFANN structure made up of activation function neurons. The back-propagation algorithm is a gradient method aiming to minimize the total operation error of the neural network. The process is intended to minimize the Error between the network output and the output actual output for the same input. The total error is a function defined by

$$
R M S=\frac{1}{2} \sum_{j}\left|t_{j}-o_{j}\right|^{2}
$$

where $t$ is target value, and $o$ is output value [10-14].

\subsection{Neural Network Advantages}

- ANNs are able to learn the key information patterns within a multi dimensional information domain.

- The inherently noisy data do not seem to cause a problem, since they are neglected. ANN models represent a new method in system prediction.

- ANNs operate like a black box model and do not require detailed information about the system.

- Instead, they learn the relationship between the input parameters and the controlled and uncontrolled variables by studying previously recorded data, similar to the way a non linear regression might perform.

- ANNs has the ability to handle large and complex systems with many interrelated parameters.

- Artificial neural networks differ from traditional simulation approaches in that they are trained to learn solutions rather than being programmed to model a specific problem in the normal way.

- They are used to address problems that are intractable or cumbersome to solve with traditional methods.

\section{Proposed Control System}

The neural network is utilized to provide the system with the required control action. Thermostatic valve is used to adjust the hot water mass flow rate through the system to control the pond temperature at $34^{\circ} \mathrm{C}$. The proposed control system consists of the ANN controller which is used to control water temperature. The control signal is used to control the operation of thermostatic valve to control the hot water flow rate added to the pond as depicted in Figure 2.

\section{ANN Control}

The proposed NN control after many trials, shown in Figure 3, eventually employed three layers which are the input layer, hidden layer, and output layer. The input layer consists of three neurones which are the air temperature, pond temperature and error, hidden layer con- 
sists of seven neurones, and output layer of one neurons as shown in Figure 3. The activation function used in this work is "logsig" for hidden layer, and "purelin" for output layer. The NN is trained using a back propagation with Levenberg-Marquardt algorithm. The Back propagation is a form of supervised learning for multi-layer nets. Error data at the output layer is back propagated to earlier ones, allowing incoming weights to these layers to be updated. It is most often used as training algorithm in current neural network applications. Figure 4 presents the mean square error between the network output and the target. The network response analysis is depicted in Figure 5. As shown in the figure the regression " $R$ " equal one which mean the output track the target in a correct way.

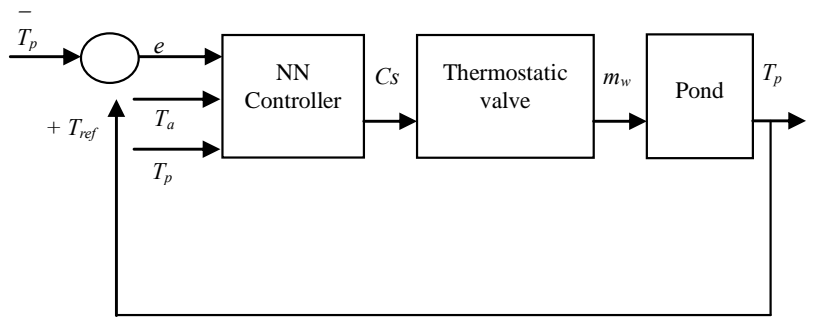

Figure 2. Block diagram of pond temperature control using NN control.
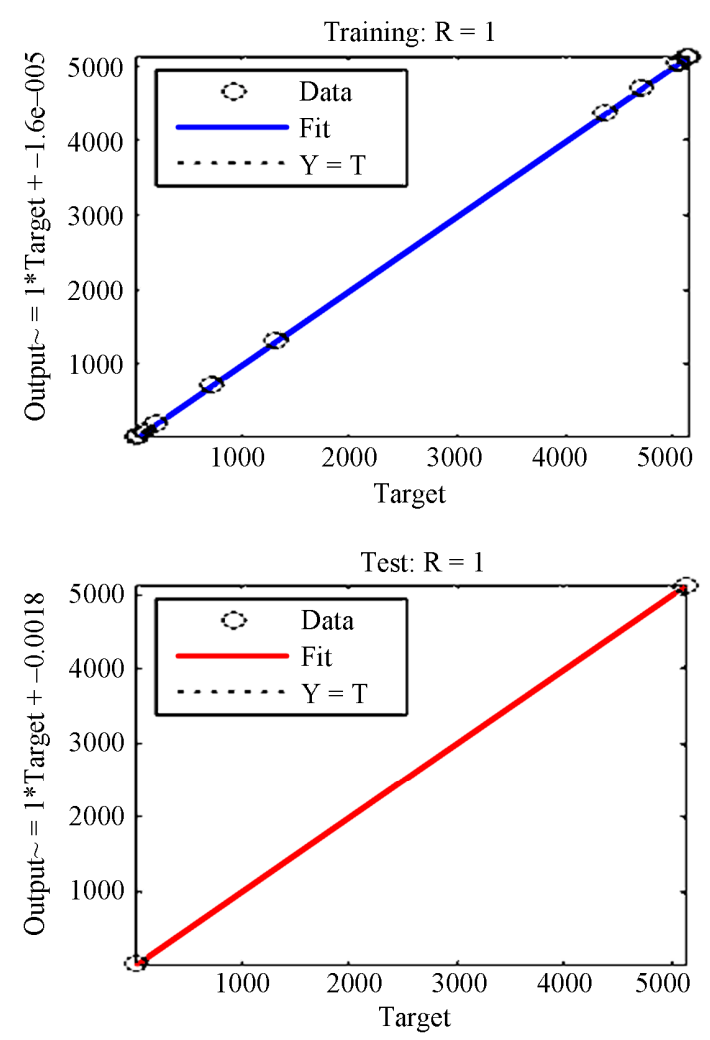

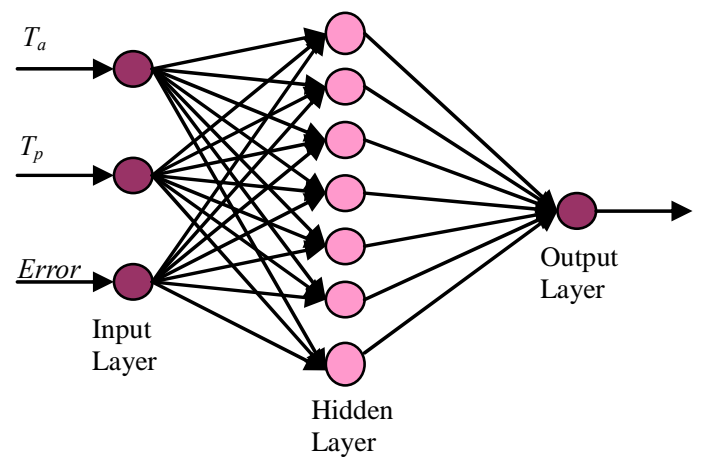

Figure 3. Neural network controller architecture.

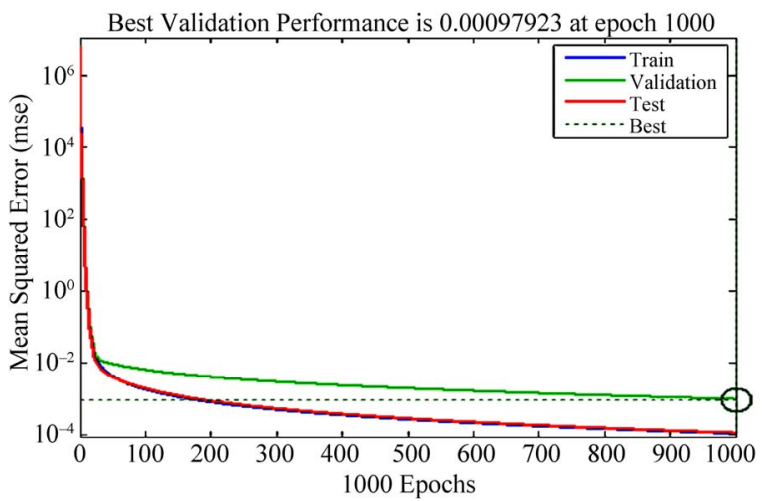

Figure 4. Mean square error.
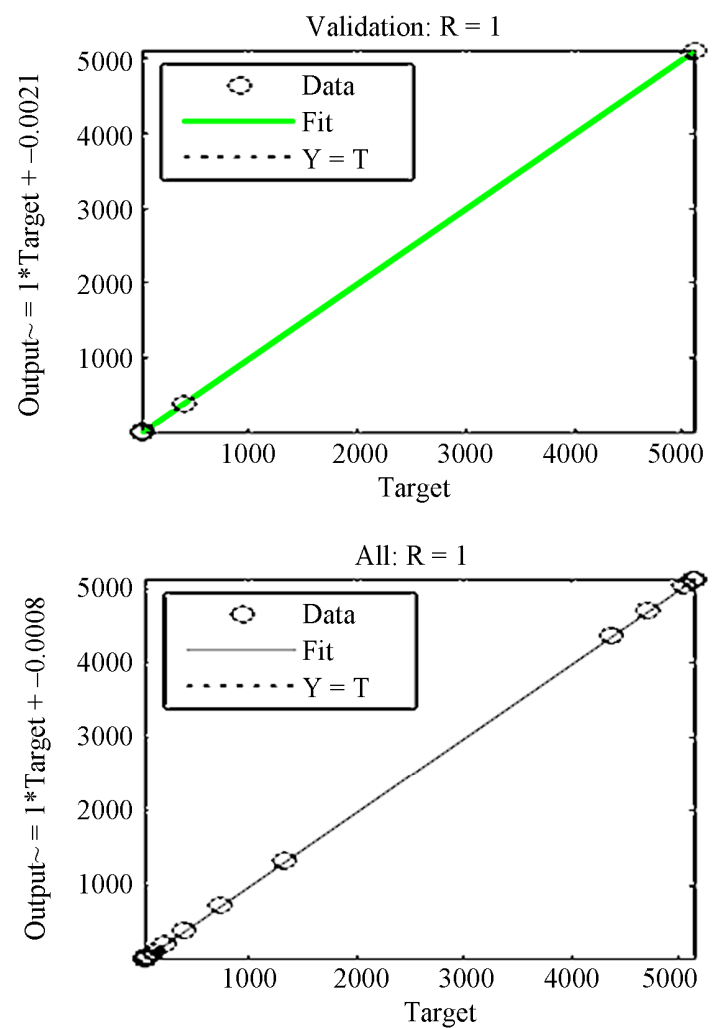

Figure 5. Regression between the network output and target. 


\section{System Simulation}

The simulation model of the proposed thermal system is depicted in Figure 6. The system consists of solar thermal subsystem to feed the system with the required hot water during the day, biogas subsystem is the auxiliary heater, pond subsystem, and finally the control subsystem. MATLAB SIMULINK of NNC is depicted in Figure 7. Figure 8 indicates the weight block diagram of layer1.

\section{Results and Discussion}

The results of the MATLAB software indicate the high capability of the proposed technique in controlling the water temperature in the aquaculture pond, even in case of changing atmospheric conditions. The system has two input parameters they are air temperature, and solar irradiance. Figure 9 and Figure 10 represent solar irradiance in Mersa Matruh the site of consideration in summer and winter respectively. Figures 11 and $\mathbf{1 2}$ show the air temperature in summer and winter.

Figures 13 and 14 indicate the pond temperature in summer and winter respectively. It is shown that the NN control has adjust the water temperature at $34^{\circ} \mathrm{C}$ without any variation during the day. Any variation in water temperature will harm the shrimp life, so the NN control has successes in this process.

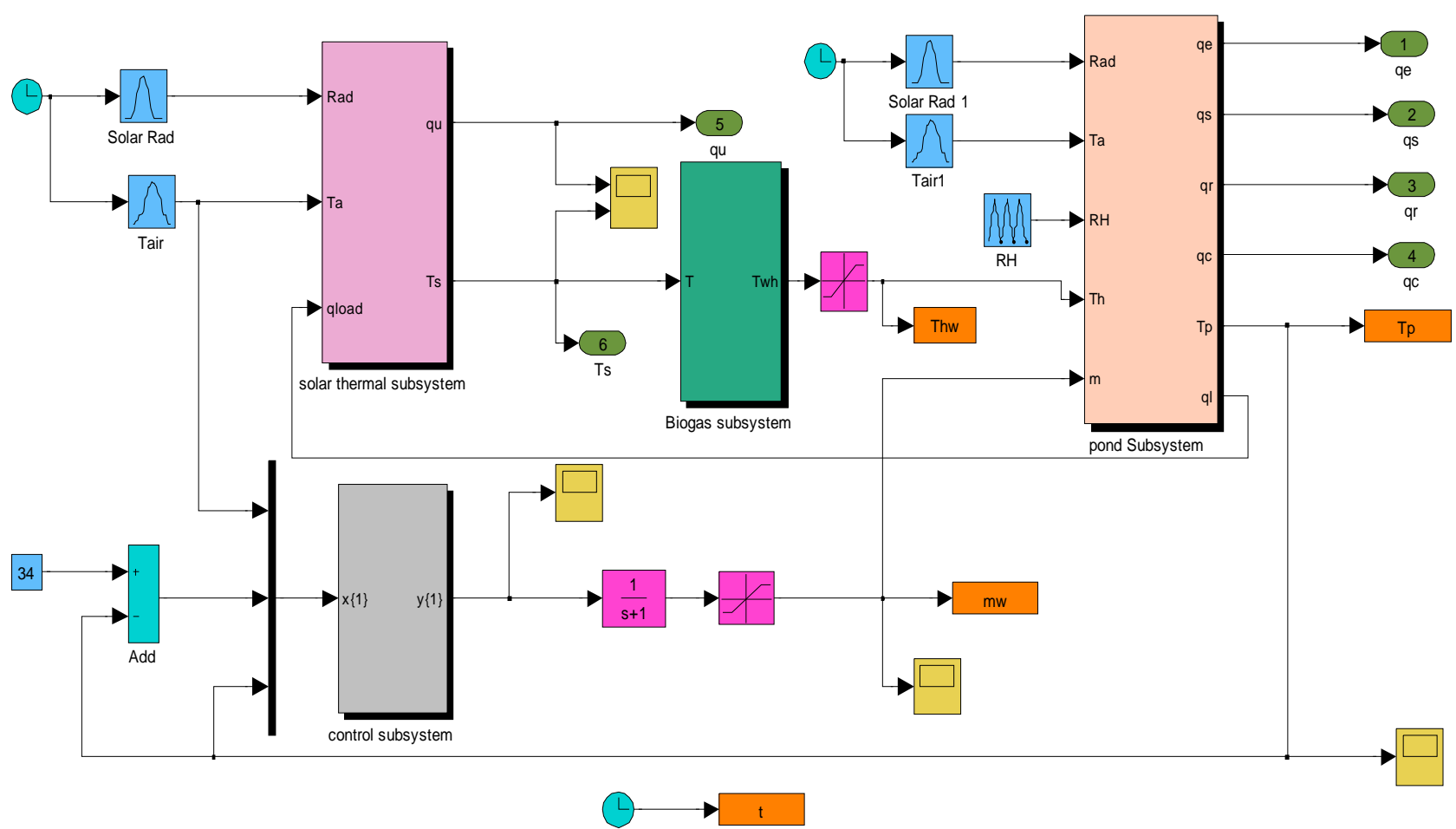

Figure 6. Solar thermal system.
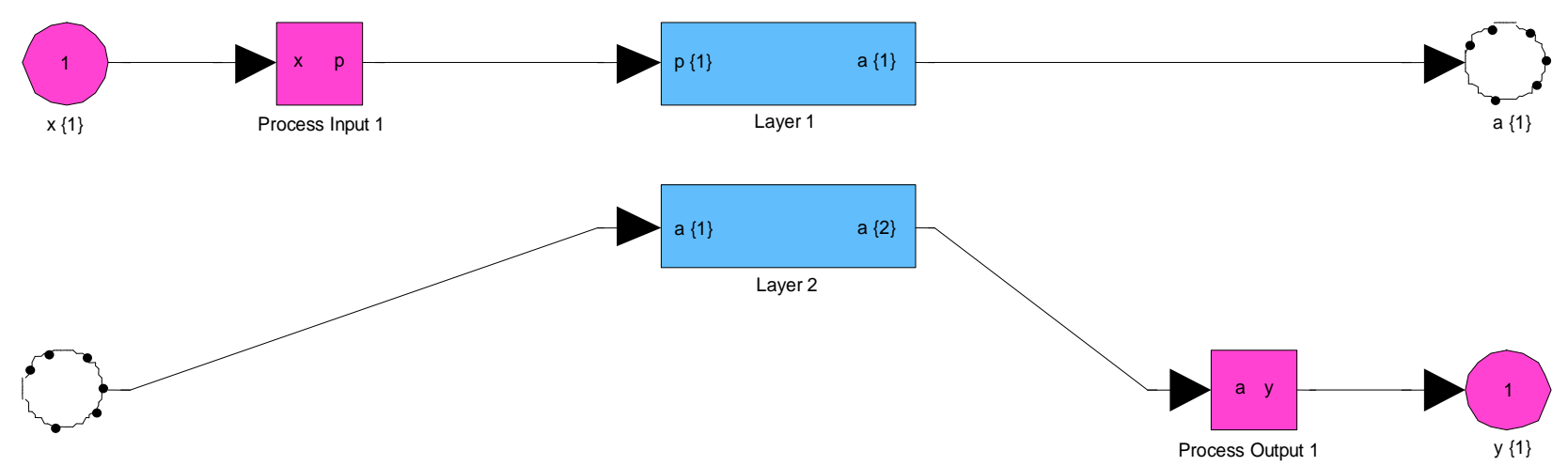

Figure 7. Neural network controller. 


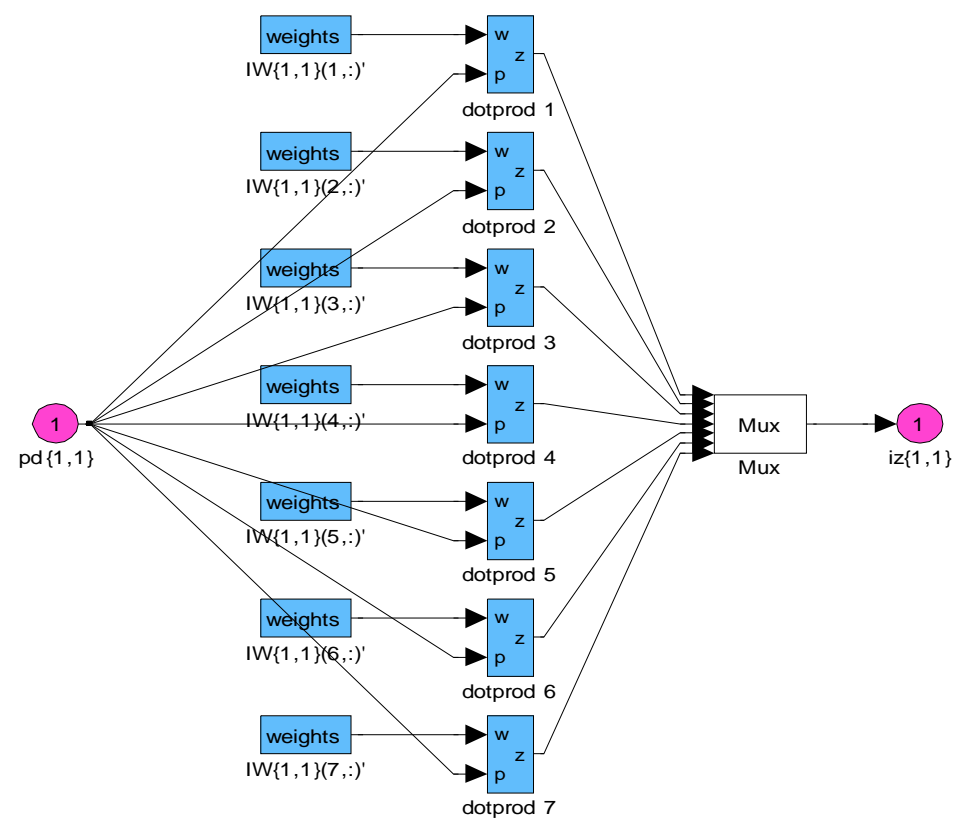

Figure 8. Block diagram of layer 1 weights.

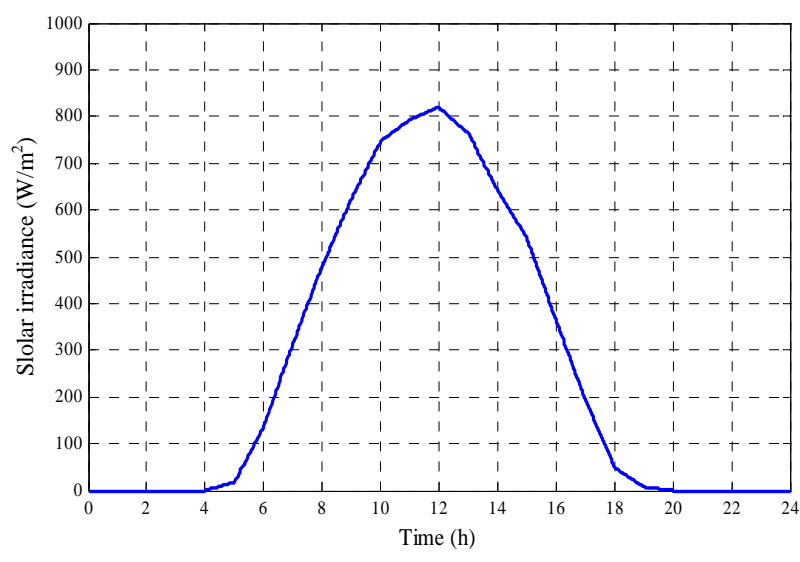

Figure 9. Solar irradiance in summer.

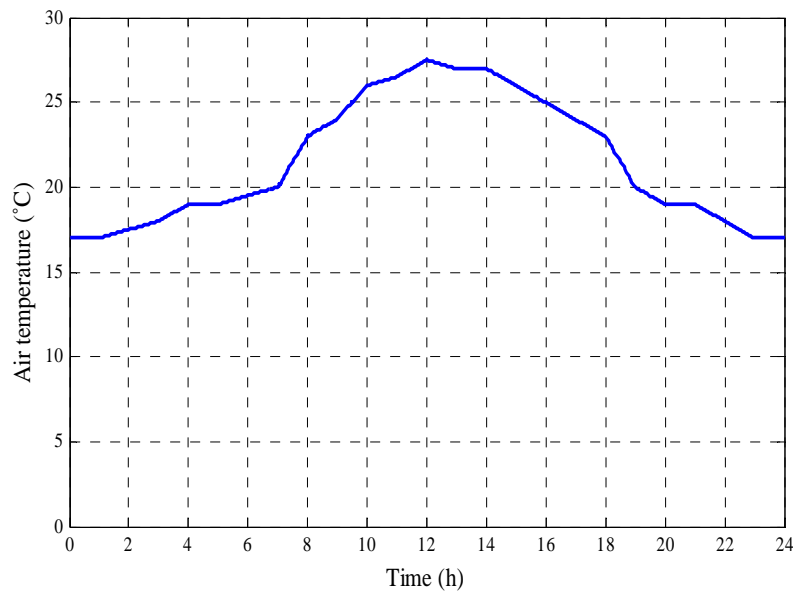

Figure 11. Air temperature in summer.

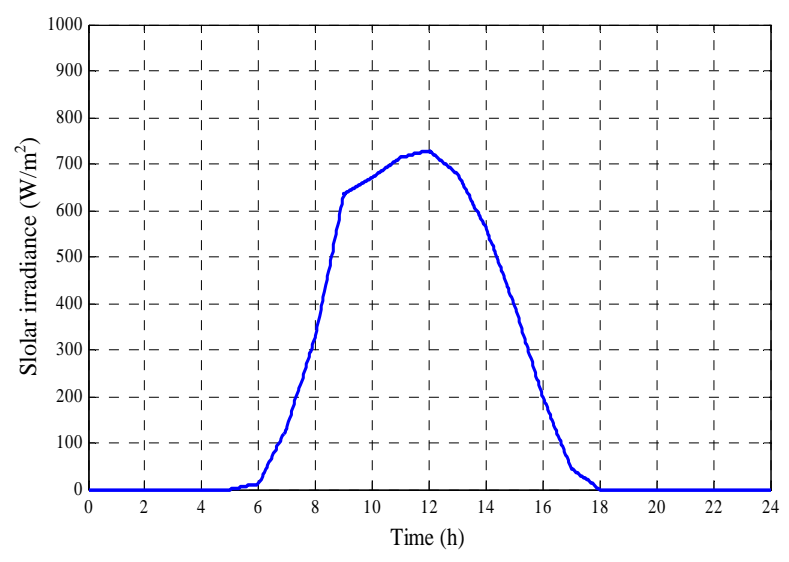

Figure 10. Solar irradiance in winter.

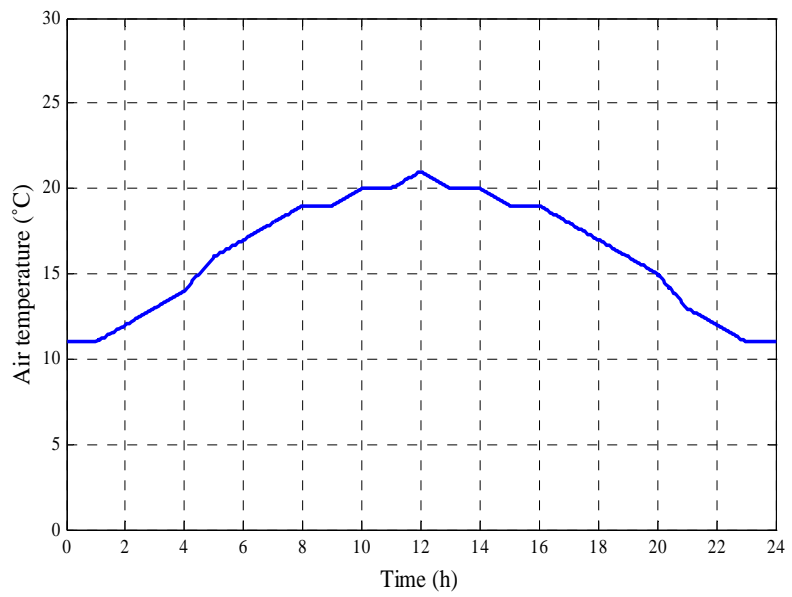

Figure 12. Air temperature in winter. 


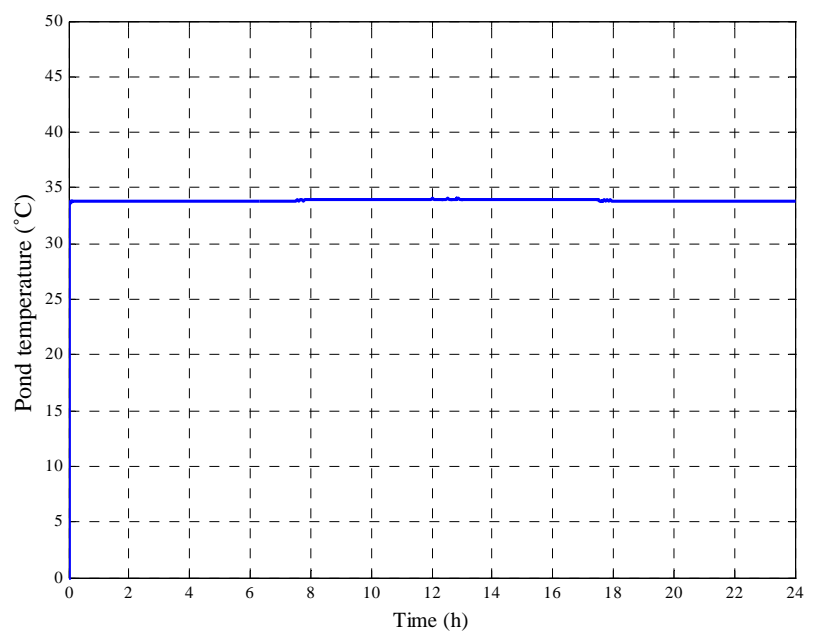

Figure 13. Pond temperature $\left({ }^{\circ} \mathrm{C}\right)$ in summer.

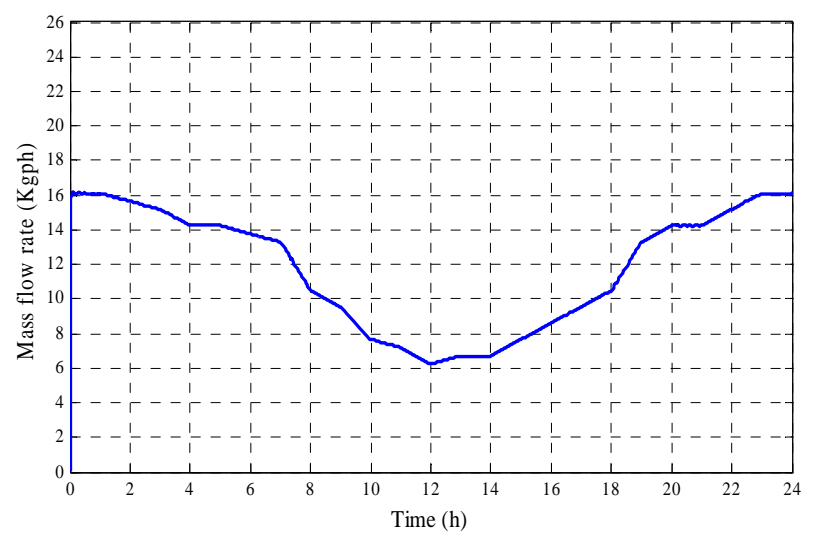

Figure 15. Mass flow rate in summer.

Figures 15 and 16 show the hot water flow rate variation over the day in summer and winter respectively. It is clear that as air temperature increase the pond temperature increase, so the value of mass flow rate decreases. During the night hours the mass flow rate has high value rather than that the day hours. The mass flow rate in winter is higher than in summer because of low air temperature in winter than in summer. The simulation results show the high efficiency of the proposed control system in control pond water temperature.

\section{Conclusiona}

The most important parameters to be monitored and controlled in an aquaculture system are related to water quality, since they directly affect animal health. Neural networks offer one such method with their ability to map complex nonlinear functions. Neural networks are massively parallel processors that have the ability to learn patterns through a training experience. Because of this

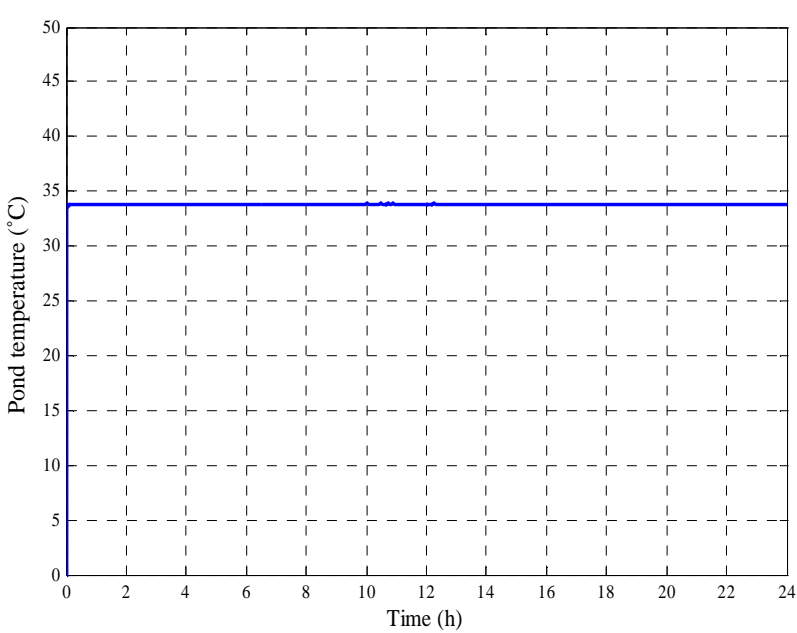

Figure 14. Pond temperature $\left({ }^{\circ} \mathrm{C}\right)$ in winter.

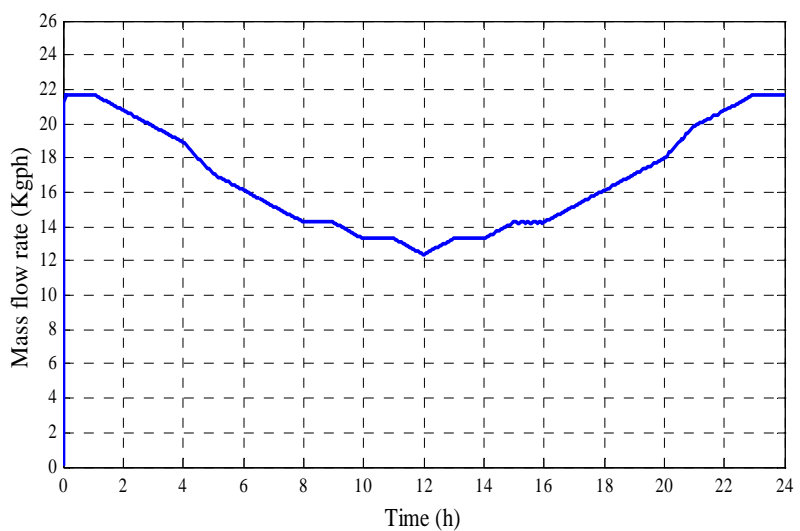

Figure 16. Mass flow rate in winter.

feature, they are often well suited for modeling complex and non-linear processes such as those commonly found in the heating system. This paper introduces the NN technique to control the water temperature of aquaculture pond. The air temperature, pond temperature, and error are used as inputs to NN control. Offline training applied with the BP has been used. The simulation results show that the feasibility of NN control in keeping water temperature constant at the desired degree $\left(34^{\circ} \mathrm{C}\right)$ by adjust the mass flow rate of hot water to the pond.

\section{References}

[1] J. J. Carbajal1 and L. P. Sanchez, "Classification Based on Fuzzy Inference Systems for Artificial Habitat Quality in Shrimp Farming," In Proceedings of IEEE Conference 7th Mexican International on Artificial Intelligence, Pachuca, 27-31 October 2008, pp. 388-392.

[2] X. J. Shena, M. Chena and J. Yub, "Water Environment Monitoring System Based on Neural Networks for Shrimp Cultivation,” In Proceedings of IEEE Interna- 
tional Conference on Artificial Intelligence and Computational Intelligence, Vol. 3, 2009, pp. 427-431.

[3] P. G. Lee, "Process Control and Artificial Intelligence Software for Aquaculture," Aquacultural Engineering, Vol. 23, No. 1-3, 2000, pp. 13-36. doi:10.1016/S0144-8609(00)00044-3

[4] S. A. Kalogeria, "Applications of Artificial Neural Networks in Energy Systems: A Review," Energy Conversion \& Management, Vol., 40, No. 10, 1999, pp. 10731087. doi:10.1016/S0196-8904(99)00012-6

[5] J. W. Moon, S. K. Jung and J.-J. Kim, “Application of Ann (Artificial-Neural-Network) in Residential Thermal Control," Building and Simulation, Proceedings of 11th International IBPSA Conference, Glasgow, 27-30 July 2009.

[6] H. Mirinejad, S. H. Sadati, M. Ghasemian and H. Torab, "Control Techniques in Heating, Ventilating and Air Conditioning (Hvac) Systems," Journal of Computer Science, Vol. 4, No. 9, 2008, pp. 777-783. doi:10.3844/jcssp.2008.777.783

[7] G. N. Kulkarni, S. B. Kedare and S. Bandyopadhyay, "Determination of Design Space and Optimization of Solar Water Heating Systems,” Solar Energy, Vol. 81, No. 8, 2007, pp. 958-968. doi:10.1016/j.solener.2006.12.003

[8] J. Gelegenis, P. Dalabakis and A. Ilias, "Heating of a Fish Wintering Pond Using Low-Temperature Geothermal
Fluids, Porto Lagos, Greece,” Geothermics, Vol. 35, No. 1, 2006, pp. 87-103.

doi:10.1016/j.geothermics.2005.10.004

[9] J. Duffie and W. Beckman, "Solar Engineering of Thermal Processes,” 2nd Edition, John Wiley \& Sons Interscience, New York, 1991.

[10] S.A Kalogiroua, S. Pantelioub and A. Dentsoras, "Artificial Neural Networks Used for the Performance Prediction of a Thermosiphon Solar Water Heater," Renewable Energy, Vol. 18, No. 1, 1999, pp. 87-99. doi:10.1016/S0960-1481(98)00787-3

[11] J. A. Freeman and D. M. Skapura, "Neural Networks Algorithms, Applications, and Programming Techniques," Addison-Wesley Publishing Company, Inc., Paris, 1991.

[12] M. N. Cirstea, A. Dinu, J. G. Khor and M. McCormick, "Neural and Fuzzy Logic Control of Drives and Power Systems,” Replika Press, Delhi, 2002.

[13] S. A. Kalogirou, "Prediction of Flat-Plate Collector Performance Parameters Using Artificial Neural Networks," Solar Energy, Vol. 80, 2006, pp. 248-259. doi:10.1016/j.solener.2005.03.003

[14] A. Sozen, T. Menlik and S. Unvar, "Determination of Efficiency of Flat-Plate Solar Collectors Using Neural Network Approach," Expert Systems with Applications, Vol., 35, No. 4, 2008, pp. 1533-1539. doi:10.1016/j.eswa.2007.08.080 